\title{
Determination of Glucose with Cellulose Acetate/Glucose Oxidase Modified Carbon Paste Electrodes
}

\author{
Rochmad Kris Sanjaya ${ }^{1}$, Datin An Nisa Sukmawati ${ }^{1}$, Nurul Ismillayli², Dhony Hermanto2," \\ 'Department of Pharmacy, Faculty of Healthy Sciences, University of Kadiri, Kediri-East Java 641 15, Indonesia \\ ${ }^{2}$ Department of Chemistry, Faculty of Mathematics and Natural Sciences, University of Mataram, Mataram
} 83125 , Indonesia

*Corresponding author email: dhony.hermanto@unram.ac.id

Received July 13, 2020; Accepted July 27, 2021; Available online November 15, 2021

\begin{abstract}
An amperometric biosensor for glucose determination was developed using a carbon paste electrode (CPE) modified with cellulose acetate (CA)/glucose oxidase (GOx) bilayer membrane through the electrostatic interaction between them. The CA membrane was used as matrix for enzyme immobilization via microencapsulation technique, is enzyme placed between two membranes. CA/GOx membrane was attached to CPE surface containing ferrocene (Fc). By using proposed amperometric biosensor, glucose concentration was determined as well as its characteristic. The modified Fc-graphite electrode with CA/GOx bilayer membrane for glucose had optimum measurement conditions at work emf of $874 \mathrm{mV}, \mathrm{CA}$ concentration of $10 \%$ and amount $\mathrm{Fc}$ of $0.021 \mathrm{mg}$. The biosensor showed good performance at glucose concentration range of 0.05-3 mM and limit of detection was $0.024 \mathrm{mM}$. Proposed biosensor has good reproducibility with relative standard deviation (RSD) was less than $5 \%$ up to 7 times use (in the defined condition $4{ }^{\circ} \mathrm{C}$ ). Glucose measurement result in human serum of diabetes mellitus patients showed conformity with result of reference method, MediSense Optium glucose test kit.
\end{abstract}

Keywords: amperometric biosensor, carbon paste electrode, CA/GOx membrane, glucose,

\section{INTRODUCTION}

One of the developing biosensors in the health sector is glucose sensor (Patel, Nanda, Sahoo, \& Mohapatra, 2016). The increasing number of people with diabetes mellitus, a metabolic disease caused by lack of insulin or inhibition of insulin secretion (Hameed et al., 2015) causes the need of analytical tool for detecting glucose levels in the body quickly, conveniently, accurately and economically is important (Yusan et al., 2018; Zhang, Du, \& Wang, 2015). Diabetes patients must control and maintain blood glucose levels within the normal range to avoid more serious complications such as neuropathy, retinopathy and stroke (Yoo, \& Lee, 2010). Hence, the biosensor for glucose-measuring tool has developed very rapidly, considering that glucose biosensors control $85 \%$ of the world biosensor market (Newman, \& Turner, 2005). Among the available glucose biosensors, electrochemical type biosensors, especially amperometric biosensors, are the most widely used because of their sensitivity, selectivity, reproducibility, low cost, simplicity and easy maintenance (Ridhuan, Razak, \& Lockman, 2018; Yoo \& Lee, 2010).

Glucose biosensors using $\mathrm{GOx}$ as a bioactive material are the most widely used method for detecting glucose levels in the body (Yoo \& Lee,
2010). GOx acts as a catalyst in the glucose oxidation reaction (Wang, Sun, Qiao, Ouyang, \& Na, 2018). Generally in amperometric biosensor based on enzymatic redox reaction (Hermanto, Kuswandi, Siswanta, \& Mudasir, 2019), a mediator was needed for transferring electron from enzyme active side to surface of electrode. Fc can be used as an oxygen substitute mediator (Cuartero, Chai, Zhang, De Marco, \& Crespo, 2019). Fc has lower oxidation potential compared to oxygen so that Fc will oxidize and not cause other biological material to oxidize (Paul, Borreli, Bouyanfif, Gottis, \& Sauvage, 2019). It was reported by Ayranci, Demirkol, Ak, \& Timur (2015), Fc was used as a redox mediator during the electrochemical measurements for glucose.

Enzyme-based biosensors have the disadvantage of limited lifetime of biosensors (Nguyen, Lee, Lee, Fermin, \& Kim, 2019). Hence, a technique is needed for long lasting and reusable enzyme such us enzyme immobilization into suitable supporting material (Hermanto, Mudasir, Siswanta, Kuswandi, \& Ismilayli, 2020; Hermanto, Kuswandi, Siswanta, \& Mudasir, 2019). GOx enzyme as molecular recognition for glucose determination was immobilized into $C A$ membrane (Wang, Zhu, \& Zhou, 2011). This research uses CA membrane because of their properties that are easy to produce, and renewable raw material. CA 
is an organic ester, widely used as a fiber, plastic, and membrane in industry (Puls, Wilson, \& Holter, 2011). Güleç, Gürda, Albayrak, \& Mutlu (2010) has modifed polyethyleneimine and $C A$ as a membrane for immobilization aspergillus oryzae $\beta$-galactosidase. While, Ansari, Satar, Zaidi, \& Ahmad (2014) has modifed poly(methyl methacrylate) and CA as matrix for the same enzyme.

Various immobilization techniques have been used in immobilizing enzymes into CA membrane (Baharifar et al., 2017; Liu \& Chen, 2016), one of them is microencapsulation techniques. In this work, bilayer CA as a matrix for GOx immobilization was prepared by microencapsulation that based on molecular interaction between enzymes and matrices. Enzymes are placed between two membrane layers. The use of two membranes in glucose biosensors is expected to increase the life time of enzymes. Enzymes are trapped inside two inert membranes so that enzymes are not easy leaching. CA/GOx membrane was attached to CPE surface containing $\mathrm{Fc}$ for purposed amperometric biosensor for glucose determination. Optimization of parameter experimental has been carried out and the analytical characteristics of the biosensor have been determined. The operational and storage stability of the biosensor were also evaluated.

\section{EXPERIMENTAL SECTION}

Chemicals used in this study include technical CA with molecular weight of $30.000 ; 39.9 \%(\mathrm{w} / \mathrm{w})$ (Brataco). GOx was isolated from Aspergillus niger (Type II, $\geq 10,000$ units/g, solid, without added oxygen) and was purchased from Sigma. Glucose anhydrous $\left(\mathrm{C}_{6} \mathrm{H}_{12} \mathrm{O}_{6}, \mathrm{KgaA}\right)$, dimethyl sulfoxide (DMSO, $\rho 1.11 \mathrm{~g} / \mathrm{mL}$ ), dimethyl phthalaxte (DMP, $\rho$ $1.19 \mathrm{~g} / \mathrm{mL})$, acetone $(\rho 0.79 \mathrm{~g} / \mathrm{mL})$, sodium hydroxide $(\mathrm{NaOH})$, sodium chloride $(\mathrm{NaCl})$ and potassium chloride $(\mathrm{KCl})$ as electrolyte solution, Fc (Merck schuchardt $\mathrm{OHG}$ ), graphite powder, paraffin oil, phosphate buffer $\mathrm{pH} \quad 7 \quad\left(\mathrm{NaH}_{2} \mathrm{PO}_{4} \cdot \mathrm{H}_{2} \mathrm{O}\right.$ and $\mathrm{Na}_{2} \mathrm{HPO}_{4}$ ), and aquadimen were received from Merck. Sample solution was prepared by appropriate dilution and all solution were diluted with deionized water. The used reagents were analytical grade.

The equipment used is a type of Home Made Potentiostat DAQ PCl $622 \mathrm{NI}$. The electrodes consist of carbon working electrodes, platinum counter electrodes, and $\mathrm{Ag} / \mathrm{AgCl}$ reference electrodes. Additional equipment consists of magnetic strirrers, Jenway 3320 pH meters, OHAU Pioneer analytical balance, cylindrical glass pipes, o-rings, permeability cells and laboratory glassware.

The CA membrane was made by using phase inversion method (Nolte et al., 2011). Membrane printing solutions consist of CA membranes with varying concentration of $10,12,14,16$ and $18 \mathrm{wt} \%$ with CA mass needed are 1.1, 1.4, 1.6, 1.9 and $2.2 \mathrm{~g}$, respectively. They were dissolved in $6.8 \mathrm{~mL}$ of DMSO,
$2.3 \mathrm{~mL}$ of acetone, $0.5 \mathrm{~mL}$ of DMP in stirring condition (400 rpm) until the solution was homogeneous. The printing solution was allowed to settle and remove air bubbles, then was poured into glass plate mold and was dipped immediately in a coagulation bath. The obtained membrane was washed with water to remove any remaining solvents and additives.

The CA membrane produced was cut in size of $3 \times$ $3 \mathrm{~cm}$. A $0.1 \mathrm{M}$ phosphate buffer solution $\mathrm{pH} 7$ containing $2.56 \times 10^{5} \mathrm{GO}$ units/L was dripped on the surface of membrane as much as $0.25 \mathrm{ml}$ and was allowed at $4{ }^{\circ} \mathrm{C}$ for 48 hours. Fc contained-carbon paste preparation refered to the method of Yusan et al. (2018), by mixing $100 \mathrm{~g}$ of graphite powder with Fc at various concentrations $(0.015 ; 0.018 ; 0.021$ and $0.024 \mathrm{~g})$. The mixture was added with a few drops of paraffin oil and homogenized using a pestle in an agate mortar. Carbon paste was put into a glass tube in right position and was connected with copper wire. Furthermore, the resistance between the copper wire at one end of the glass pipe and the carbon paste at the other end of the glass tube was measured and the resistance was less than $20 \mathrm{Ohm}$.

The surface of Fc contained-carbon electrode was coated with a membrane that was immobilized by the GOx enzyme at concentration of $2.56 \times 10^{5}$ units/L and was resurfaced with $C A$ as outer membrane using o-rings to form CA bilayer biosensor. The used electrochemical cells consisted of beaker glass, biosensor working electrodes with CA bilayer membrane, $\mathrm{Ag} / \mathrm{AgCl}$ reference electrodes and platinum wire counter electrodes with $0.5 \mathrm{M} \mathrm{NaCl}$ solution. Biosensing of bilayer acetate cellulose was carried out by measuring standard glucose solution (with varies consentration were $0.05,0.1,1,2$ and 3 $\mathrm{mM}$ ) using an amperometer.

The optimization of several biosensor parameters such as membrane concentration, emf, mass of $\mathrm{Fc}$ and response time were carried out. The optimum membrane concentration was determined with varying concentrations from 10-18 wt\%; emf was varied from 0.01-1.00 V; varied of Fc mass was 0.015-0.024 g and response time was measured at 0-260 $\mathrm{s}$ at optimum membrane concentrations, emf and Fc mass. The optimum conditions obtained are used to determine the analytical performance of the biosensor including linearity, limit of detection, repeatability, stability and interference.

\section{RESULTS AND DISCUSSION}

The mechanism of reaction between glucose, $\mathrm{GO}_{x}$ enzymes and $F c$ is described in the following scheme; Glucose + $\mathrm{GOx}_{(\mathrm{ox})} \rightarrow$ Gluconolactone + $\mathrm{GOx}_{\text {(red) }}$ (1)

Glucose $+\mathrm{FAD} \rightarrow$ Gluconolactone $+\mathrm{FADH}_{2}$

$\mathrm{GOx}_{\text {(red) }}+2 \mathrm{Fc}^{+} \rightarrow \mathrm{GO}_{\text {(ox) }}+2 \mathrm{Fc}+2 \mathrm{H}^{+}$

$2 \mathrm{Fc} \rightarrow 2 \mathrm{Fc}^{+}+2 \mathrm{e}$

Where $\mathrm{Fc}^{+}$and $\mathrm{Fc}$ are oxidized and reduced forms of ferrosene. $F_{c}$ is an electron transfer mediator undergoing an oxidation reaction by releasing 
electrons after being given potential, become $\mathrm{Fc}^{+}$ion. The electrons was released, GOx enzyme oxidized $\beta$ D-Glucose to D-Glucono-1,5-lactone by releasing two electrons in the form of hydrogen atom (Eq. 1). FAD as cofactor of the GOx enzyme received two hydrogen atoms and undergo reduction reaction to $\mathrm{FADH}_{2} . \mathrm{FADH}_{2}$ then was oxidized by transferring electrons to become FAD (Eq. 2). The electrons transferred by $\mathrm{FADH}_{2}$ were then captured by the $\mathrm{Fc}^{+}$ ion for reduction reaction and became Fc (Eq. 3). Fc then undergo an oxidation reaction again after being given potential through an amperometer and releasing electrons (Eq. 4). The basic principle of sensing glucose biosensor is shown in Figure 1.

The amount of released and used electrons to force the GOx enzyme oxidizes $\beta$-D-Glucose to D-Glukono1,5-lactone was detected as measured current, was proportional to the amount of oxidized glucose. The measured current was the result of the Fc oxidation reaction, so this current was called the Fc oxidation current. The glucose oxidation reaction in one glucose molecule would transfer two electrons to one GOx enzyme molecule. Oxidation of one molecule of $\beta-D$ glucose to D-gluconolactone required two molecules of $\mathrm{Fc}^{+}$ions that reduced to $\mathrm{Fc}$.

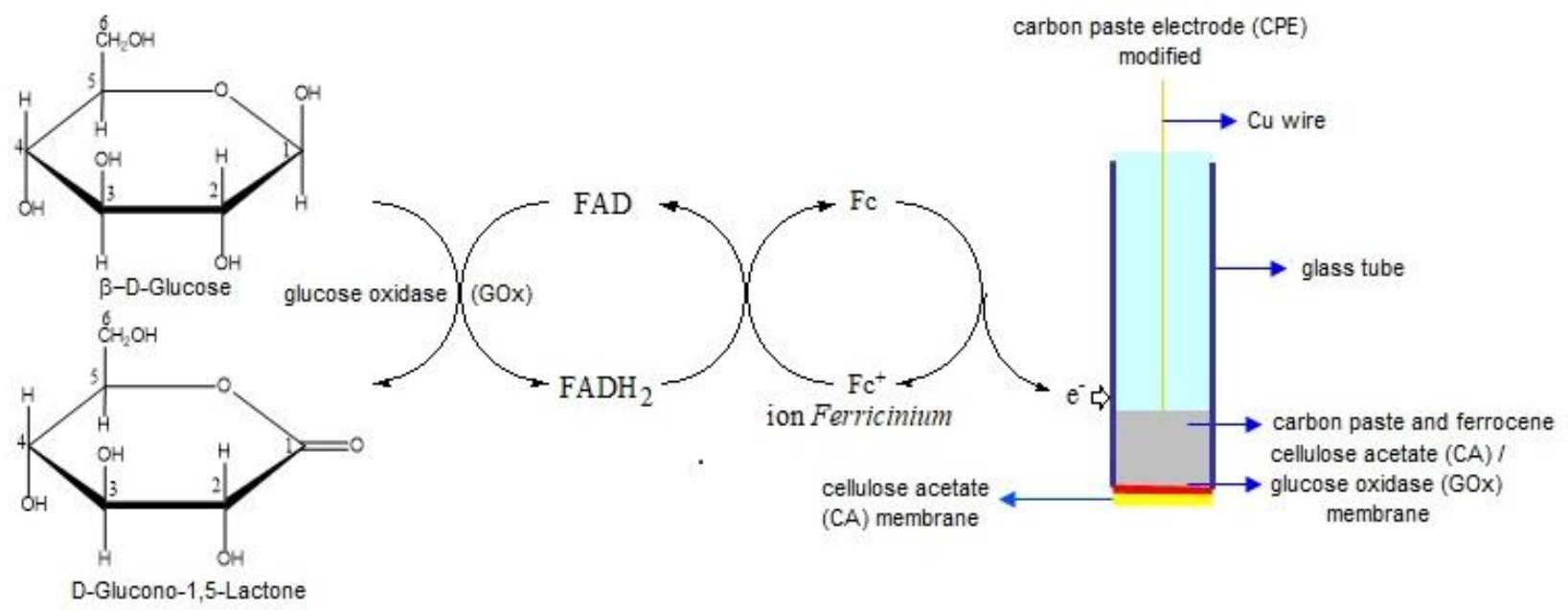

Figure 1. Schematic illustration of sensing principle in glucose biosensor including fabrication of modified Fc-graphite electrode with CA/GOx bilayer membrane.

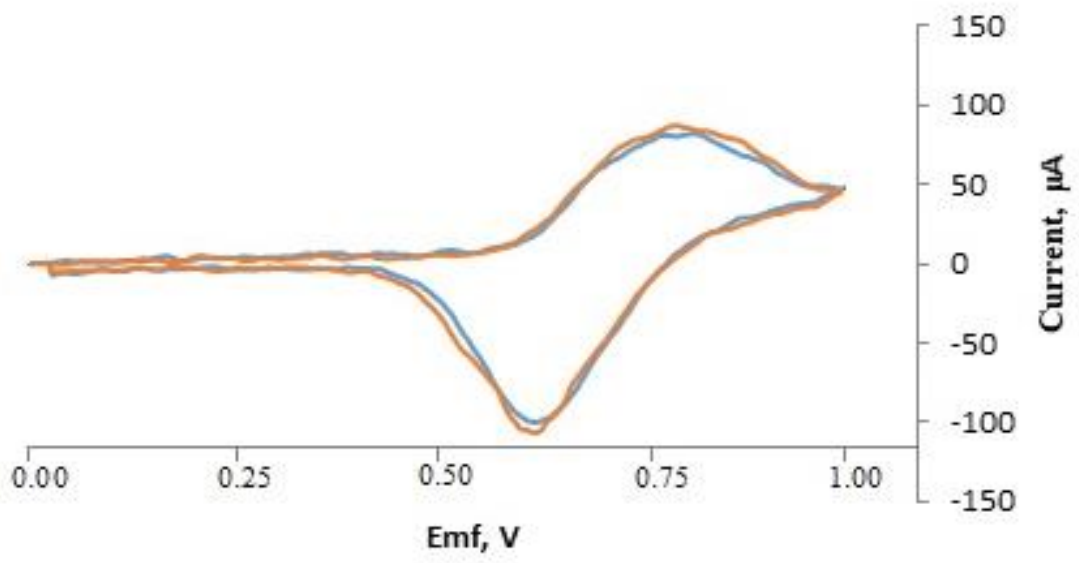

Figure 2. Cyclic voltamogram of modified Fc-graphite electrode with CA/GOx bilayer membrane at 0.01 to $1.0 \mathrm{~V}$ vs $\mathrm{Ag} / \mathrm{AgCl}$, sweep rate was $5 \mathrm{mV} / \mathrm{s}$, and $\mathrm{Fc}$ mass was $0.021 \mathrm{~g}$.

Table 1. Optimization of amperometric biosensor parameters

\begin{tabular}{lcc}
\hline Parameter & Range & Optimum Value \\
\hline Membrane Concentration (wt\%) & $10-18$ & 10 \\
Emf (V) & $0.01-1.0$ & 0.874 \\
Mass Fc (g) & $0.015-0.024$ & 0.021 \\
Response Time (s) & $0-260$ & 70 \\
\hline
\end{tabular}


Based on Figure 2, the used emf between 0.01 to $1.1 \mathrm{~V}$ produced positive current value, indicated that Fc was oxidized to $\mathrm{Fc}^{+}$by releasing electrons, thus increased the current value. The $\mathrm{NaCl}$ current was showed by blue line, while red line was current when glucose was added.

In terms of increased performance of the modified Fc-graphite electrode with CA/GOx bilayer membrane as an amperometric biosensors, there are many parameters affecting the sensor response such us membrane concentration, emf, mass Fc and response time. The optimization of the experimental parameters is an essential step in the analytical characteristics of the modified Fc-graphite electrode with CA/GOx bilayer membrane as an amperometric biosensors performance. Table 1 shows some investigated-experimental parameters and their optimum value.

The membranes used in this study vary in concentration, ie 10, 12, 14, 16 and 18 wt\%. Based on the research results was shown in Table 1, the optimum membrane concentration has the highest reduction in glucose was 10 wt\% CA membrane with a concentration of $23.73 \times 10^{-3} \mathrm{mmol}$ or $10 \mathrm{wt} \%$ has the highest permeability to glucose compared to other membranes, due to their higher porosity. An increase in CA membrane concentration caused glucose permeability decrease. Increasing the concentration of polymer in the casting solution affected the polymer concentration in interface and polymer volume fraction increased, hence produced membrane has smaller surface porosity. Otherwise, at CA concentrations was smaller than 10 wt\% would produce membranes with larger pore distributions. The resulting membrane was thinner and more brittle so it was easily torn. CA membrane in this biosensor as well as enzyme immobilization medium was also used as a filtration membrane in the measurement of glucose levels in blood serum (Idris, Yee, \& Kee, 2015).

Cyclic voltammogram Figure 2 shows that emf between 0.0 to $1.1 \mathrm{~V}$ give positive current value. This showed that $\mathrm{Fc}$ was oxidized to $\mathrm{Fc}^{+}$by releasing electrons and resulted in current increasing. At emf of $0.63 \mathrm{~V}$ an increase in current begins to be detected, indicating $\mathrm{Fc}$ was starting to oxidize. The current increasing would continue until the emf of $0.874 \mathrm{~V}$ was achieved, which is the optimum emf with the most oxidized Fc. At higher emf, ie 0.874 to $1.1 \mathrm{~V}$ the measured current decreased because Fc was oxidized decreasing. Giving an emf between 1.1 to $0.0 \mathrm{~V}$ produced negative current, showed the reduction reaction. A decrease in current occured slowly and optimum current decreased was attained at $0.683 \mathrm{~V}$. The decrease in current shows the number of reduced $\mathrm{Fc}^{+}$ions to $\mathrm{Fc}$ were the most so that the required electrons were also in large number, resulting current decreasing. While, increasing current was recorded at 0.683-0.00 V due to decrease in reduction of $\mathrm{Fc}^{+}$ion to Fc. Based on the voltammogram above, Fc undergo reversible oxidation-reduction reaction so that it can be used as mediator of electron transfer from enzymes to the working electrodes of glucose biosensors. The use of membrane bilayers in glucose biosensors caused longger time of glucose to diffuse before bounding to the active site of enzyme, causing small current detected due to the lack of oxidized glucose. Immobilization of enzymes in the membrane also limited the enzyme's motion and influenced enzyme activity. Glucose in the bilayer biosensor oxidized, releasing electrons which later were used in the reduction reaction of the $\mathrm{Fc}^{+}$ion to $\mathrm{Fc}$. The optimum emf value of $\mathrm{Fc}$ was used in the measurement of amperometer to oxidize Fc.

Fc as electron transfer mediator in the glucose oxidation-reduction reaction which is catalyzed by the GOx enzyme influence current produced. The more $\mathrm{Fc}$, the more the capacity of receiving and transferring electrons cause the higher current produced. At Fc mass of 0.015 and $0.018 \mathrm{~g}$, the currents increased 3.558 and $4.137 \mathrm{~mA}$ respectively. The Fc mass of $0.021 \mathrm{~g}$ was optimum Fc mass, providing the highest current increase, was $5.584 \mathrm{~mA}$, meaning that all electrons could be transferred to working electrode. Applying higher $\mathrm{Fc}$ of $0.024 \mathrm{~g}$ decreased the measured current of $3.855 \mathrm{~mA}$. This is probably due to the excessive number of $\mathrm{Fc}^{+}$ions formed due to increased amount of Fc. The amount of excess $\mathrm{Fc}^{+}$ions when compared to the number of transferred electrons would cause competition, hence disrupted the rate of electron transfer and caused decrease in current.

At emf $0.874 \mathrm{~V}$, the modified Fc-graphite electrode with CA/GOx bilayer membrane as an amperometric biosensors showed response changes in the presence of glucose. The response time of the modified Fcgraphite electrode with CA/GOx bilayer membrane to various concentrations of glucose solutions at emf $0.874 \mathrm{~V}$ is given in Table 1 . As a reference, it was used modified Fc-graphite electrode with CA/GOx bilayer membrane that was not treated with glucose. It was observed that the $70 \mathrm{~s}$ response time was the optimal time to reach $90 \%$ current response so it was used for further measurements.

Based on Figure 3, $\mathrm{NaCl}$ currents marked with blue lines were blank currents. The addition of glucose caused increasing current occurred slowly until constant value was reached. Giving higher concentrations of glucose solutions resulted higher detected currents due to the increasing amount of glucose which was oxidized by enzymes. The response of modified Fc-graphite electrode with CA/GOx bilayer membrane has been investigated under optimum conditions. The modified Fc-graphite electrode with CA/GOx bilayer membrane response graph showed changes of amperometric current due to glucose standard concentration. As shown in Figure 3, the amperogram graph of the biosensor for successive addition of glucose standard solution. The inset shows the plot of the calibration curve between the 
amperometric currents and concentration of glucose has good linearity with the correlation coefficient, $r=$ 0.9976 . It means that $R^{2}$ close to 1 (resulted curve was linear). The regression coefficient resulting from the graph was 0.9976 . This indicated that $99.76 \%$ of the emf change produced was influenced by changes in glucose concentration and $0.24 \%$ was influenced by other factors. The modified Fc-graphite electrode with CA/GOx bilayer membrane in glucose measurement with concentration range of $0.05-3 \mathrm{mM}$ has linear regression equation, which is $y=0.2906 x+0.5753$. The measured current increase was the oxidation current of Fc. The resulting linear correlation occurred in the range of glucose concentrations between 0.05 $3 \mathrm{mM}$. In the measurement of amperometric biosensor, t he emf used was $0.874 \mathrm{~V}$, as shown in Figure 3 (inset). The sudden emf giving of $0.874 \mathrm{~V}$ on the amperometer caused change in charging current comparing to voltmeter. It was likely due to the power amplifier on the potentiostat had not reached the expected emf value, so measured charging current has decreased, resulted decrease in the measured $\mathrm{NaCl}$ current.

The detection limit is the smallest concentration of an analyte (glucose) can be determined or detected. The smaller the detection limit, the better biosensor performance. In this study, the detection limit was determined from the intercept of the calibration curve plus three times its standard deviation (Miller \& Miller, 2005). Limit detection of modified Fc-graphite electrode with CA/GOx bilayer membrane was 0.024 $\mathrm{mM}$. Biosensor sensitivity as the ratio of signal changes per unit changes in analyte concentration is determined based on the slope value of the calibration curve. Based on the calibration curve, the sensitivity value of the modified Fc-graphite electrode with CA/GOx bilayer membrane was $0.290 \mu \mathrm{A} / \mathrm{mM}$. A large sensitivity value means that small change in concentration of an analyte can provide meaningful response so the higher the sensitivity the more sensitive the method.

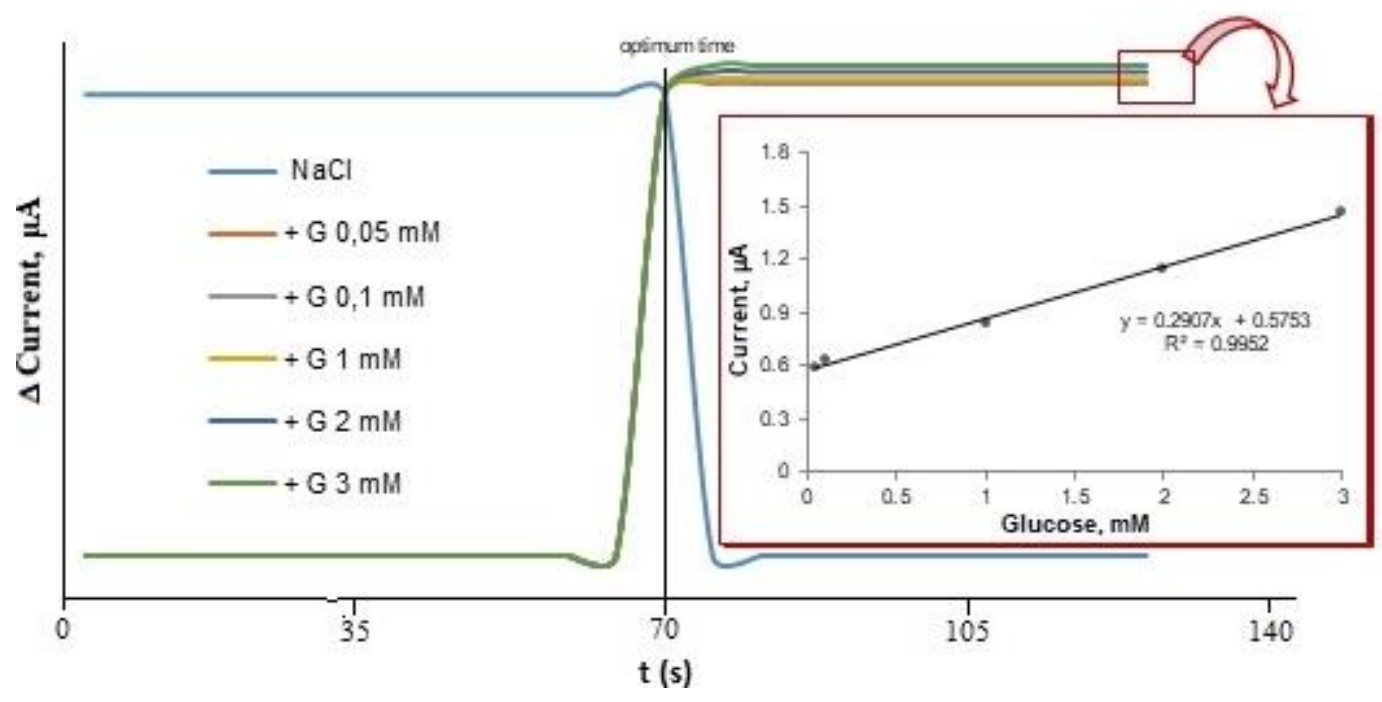

Figure 3. Amperogram graph of current increase. Measurements were made using an amperometer at 0.874 $\mathrm{V}$, with $0.5 \mathrm{M} \mathrm{NaCl}$ electrolyte solution blank and $0.05,0.1,1,2$, and $3 \mathrm{mM}$ glucose standard solution. (inset) a plot calibration of amperometric biosensor response vs. glucose concentration.

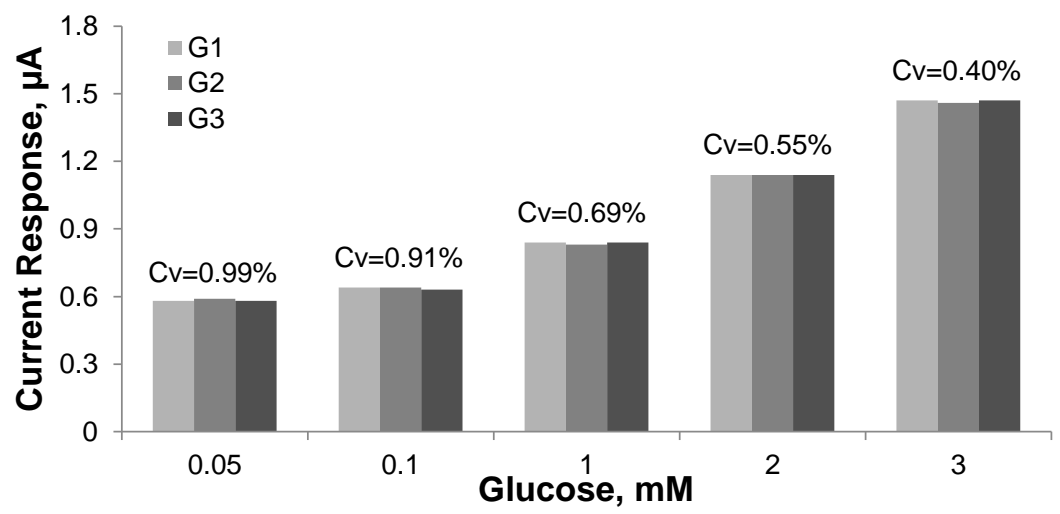

Figure 4. The glucose amperometric biosensor response toward reproducibility at various concentration of glucose (amperometer measurement at $0.874 \mathrm{~V}$, with $0.5 \mathrm{M} \mathrm{NaCl}$ electrolyte blank solution and $0.05,0.1,1$, 2 , and $3 \mathrm{mM}$ glucose standard solution, and $\mathrm{n}=3$ ). 
The reproducibility of biosensors as important characteristics were studied in this work. Reproducibility is biosensor's ability to provide close agreement between measurment results using same method in different condition. Repetition of experiments is expected to produce difference result between experiments as small as possible or resulting precise data. The reproducibility of the modified Fcgraphite electrode with CA/GOx bilayer membrane as an amperometric biosensor was determined by doing 3 measurements using 3 membranes $(n=3, G 1=$ first membrane to $\mathrm{G} 3$ = third membrane). The results showed that the reproducibility in the concentration range of $0.0-3.0 \mathrm{mM}$, was 0.0 to $0.99 \%$, which indicate that the biosensor has excellent reproducibility, as shown in Figure 4.

The biosensor stability is carried out every days by observing modified Fc-graphite electrode with CA/GOx bilayer membrane current response to glucose as shown in Figure 5. During stability test, the membrane was stored at $4^{\circ} \mathrm{C}$. It was found that for 7 days modified Fc-graphite electrode with CA/GOx bilayer membrane response decreased 23\%, indicating that modified Fc-graphite electrode with CA/GOx bilayer membrane was good stability membrane. In the 8 day measurement the ratio of measured current response to initial current response was $55 \%$. Possibly caused by activity decrease of GOx enzyme, hence the response to glucose also decreased and measured current also decreased by $45 \%$. Thus, the biosensor has life time 7 days when stored at defined condition $\left(4^{\circ} \mathrm{C}\right)$.

Method selectivity was determined by adding a different amount of the potentially interfering substances containing other substrate that generally find in clinical analysis such as cholesterol, creatinine, uric acid, maltose and ascorbic acid (Yoo \& Lee, 2010). Table 2 shows an activity of the amperometric biosensor on several interferences. The analysis was conducted with the concentration ratio of glucose with the interference substrate was 1:10 (1 $\mathrm{mM}$ of glucose, $10 \mathrm{mM}$ interference). The current response relative value was very small $(<5 \%)$, indicating that other substrates have no significant effect at this ratio. However, ascorbic acid has a relatively larger value compared to other interference substrate. Ascorbic acid at this concentration could affect the redox activity of electrode, whereas ascorbic acid is oxidized at the electrode surface, resulting in the production of more electrons and generate greater current. The comparison of the biosensor performance with the previous glucose biosensor is shown in Table 3 .

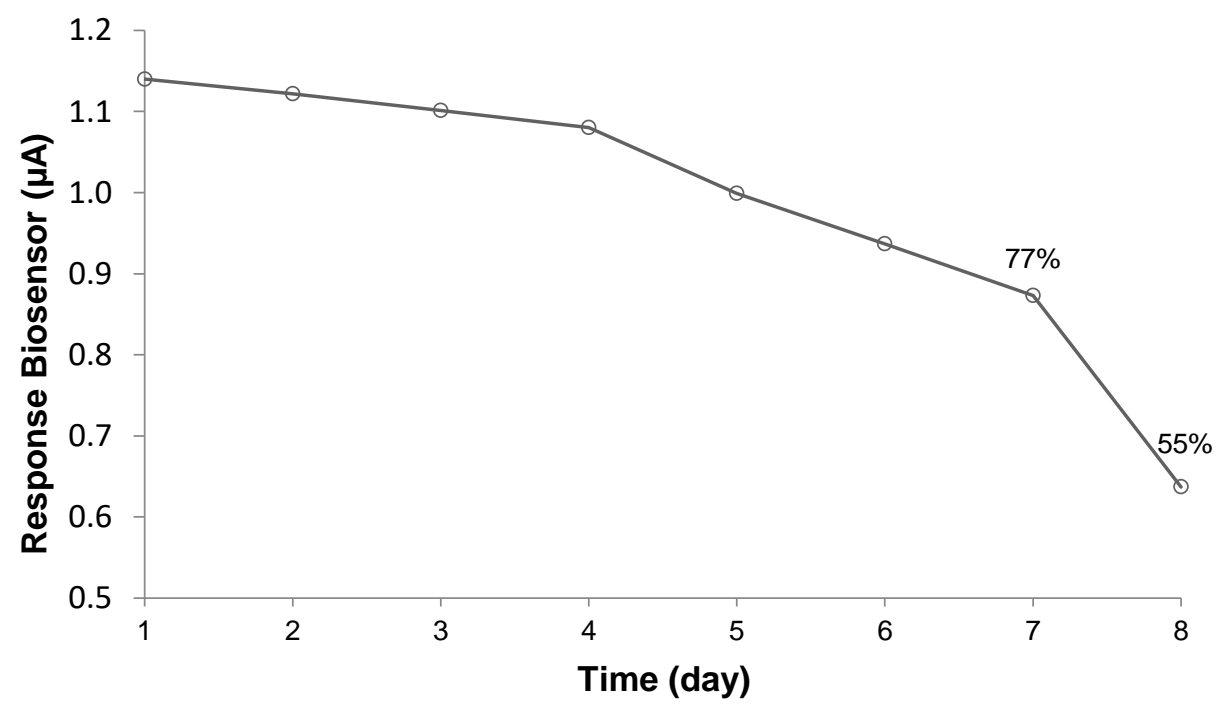

Figure 5. The curve of decreased current response to glucose

Table 2. Determination results of possible interferences tested with the biosensor.

\begin{tabular}{cc}
\hline Interference & Relative Redox Activity (\%) \\
\hline Cholesterol & +0.79 \\
Creatinine & +0.68 \\
Uric acid & +1.10 \\
Maltose & +1.25 \\
Ascorbic acid & +1.66 \\
\hline
\end{tabular}


Table 3. Comparasion of many glucose biosensor performance.

\begin{tabular}{lccccc}
\hline \multicolumn{1}{c}{ Electrode mateials } & Linearity & LOD $(\mathrm{mM})$ & $\begin{array}{c}\text { RSD } \\
(\%)\end{array}$ & Time $(\mathrm{s})$ & Reference \\
\hline Fc-graphite/CA/GOx & $0.05-3.00$ & 0.0240 & 0.99 & 70 & This work \\
Nafion/Gox/ZnO NR & $0.05-1.00$ & 0.0600 & 3.03 & 10 & Ridhuan et al., 2018 \\
Se-MCM-41/GOD/CPE & $0.01-2.00$ & 0.1000 & 2.8 & $\mathrm{n} / \mathrm{a}$ & Yusan et al., 2018 \\
GOD/CS-rGO/AuNPs/Pt & $0.015-2.13$ & 0.0017 & 3.2 & 5 & Fang et al., 2015 \\
\hline
\end{tabular}

Table 4. Glucose levels in clinical analysis using amperometric biosensor and MediSense glucose test strips.

\begin{tabular}{lcc}
\hline Parameter & $\begin{array}{c}\text { Modified Fc-graphite electrode with } \\
\text { CA/GOx bilayer membrane }\end{array}$ & $\begin{array}{c}\text { MediSense optium point of care blood } \\
\text { glucose test strips }\end{array}$ \\
\hline X1 (mg/dL) & 117 & 124 \\
X2 (mg/dL) & 113 & 123 \\
X3 (mg/dL) & 102 & 122 \\
Average & 110.67 & 123 \\
STDEV & 7.77 & 4.31 \\
CV (\%) & 7.0 & 3.5 \\
\hline
\end{tabular}

To find out the performance of amperometric biosensors in real samples, biosensor was used to measure the concentration of glucose in clinical samples, namely serum of diabetes mellitus sufferers. By using method of standard addition, number of samples that had been added glucose with certain concentration were analyzed. The measurement results given in Table 4, show that the developed electrochemical biosensor has measurement results that are in accordance with the measurement results using an amperometric method that is often used for clinical analysis, glucose test kit (MediSense optium point of care blood glucose test strips, Abbott Diabetes Care Limited, UK) as reference. This shows that modified Fc-graphite electrode with CA/GOx bilayer membrane has very good characteristics to determine glucose in human serum. Hence, modified Fcgraphite electrode with CA/GOx bilayer membrane as amperometric biosensor can be used as analytical tool for glucose determination.

\section{CONCLUSIONS}

An amperometric biosensor for glucose determination has been developed through a modified Fc-graphite electrode with CA/GOx bilayer membrane. The optimum conditions biosensor membrane obtained were measurements at emf of $0.874 \mathrm{mV}$ with CA concentration of $10 \%$ and Fc mass of $0.021 \mathrm{gram}$. Under its optimum conditions, current respons of modified Fc-graphite electrode with CA/GOx bilayer membrane as an amperometric biosensor was linear to glucose concentrations at concentrations range of $0.05-3.00 \mathrm{mM}$ and the limit of detection was $0.024 \mathrm{mM}$. During measurements, the biosensor has good reproducibility (RSD was less than $5 \%)$ and high sensitivity $(0.291 \mu \mathrm{A} / \mathrm{mM})$ for up to seven uses. The modified Fc-graphite electrode with CA/GOx bilayer membrane as an amperometric biosensor can be used as analytical tool for glucose determination indicated by accordance result of biosensor measurement with value of glucose test kit measurement as reference method in glucose determination in human serum samples. promising biosensor design for glucose determination.

\section{REFERENCES}

Ansari, S. A., Satar, R., Zaidi, S. K., \& Ahmad, A. (2014). Immobilization of Aspergillus oryzaegalactosidase on cellulose acetatepolymethylmethacrylate membrane and its application in hydrolysis of lactose from milk and whey. International Scholarly Research Notices, 2014, 1-6.

Ayranci, R., Demirkol, D. O., Ak, M., \& Timur, S. (2015). Ferrocene-functionalized 4-(2,5di(thiophen-2-yl)-1H-pyrrol-1-yl)aniline: a novel design in conducting polymer-based electrochemical biosensors. Sensors, 15, 13891403.

Baharifar, H., Honarvarfard, E., Malek-kheili, M. H., Maleki, H., Barkhi, M., Ghasemzadeh, A., \& Kamyar, K. (2017). The Potentials and applications of cellulose acetate in biosensor technology. Nanomedicine Research Journal, 2(4), 216-223.

Cuartero, M., Chai, L., Zhang, B., De Marco, R., \& Crespo, G. A. (2019). Ferrocene self assembled monolayer as a redox mediator for triggering ion transfer across nanometer-sized membranes. Electrochimica Acta, 315, 84-93.

Fang, Y., Zhang. D., Guo, Y., Guo, Y., \& Chen, Q. (2015). Simple one-pot preparation of chitosan-reduced graphene oxide-Au nanoparticles hybrids for glucose sensing. Sensors and Actuators B: Chemical, 221, 265272

Güleç, A., Gürda, S., Albayrak, N., \& Mutlu, M. (2010). Immobilization of Aspergillus oryzae B- 
galactosidase on low- pressure plasmamodified cellulose acetate membrane using polyethyleneimine for production of galactooligosaccharide. Biotechnology and Bioprocess Engineering, 15, 1006-1015.

Hameed, I., Masoodi, S. R., Mir, S. A., Nabi, M., Ghazanfar, K., \& Ganai, B. A. (2015). Type 2 diabetes mellitus: from a metabolic disorder to an inflammatory condition. World Journal of Diabetes, 6(4), 598-612.

Hermanto, D., Kuswandi, B., Siswanta, D., \& Mudasir. (2019). Inhibitive determination of $\mathrm{Hg}(\mathrm{II})$ in aqueous solution using urease amperometric biosensor. Indonesian Journal of Chemistry, 19(3), 786-795.

Hermanto, D., Mudasir, M., Siswanta, D., Kuswandi, B., \& Ismilayli, N. (2019). Polyelectrolyte complex (PEC) of the alginate-chitosan membrane for immobilizing urease. Journal of Mathematics and Fundamental Sciences, $51(3)$, 309-319.

Hermanto, D., Mudasir, M., Siswanta, D., Kuswandi, B., \& Ismillayli, N. (2020). The preparation and characterization of alginate-chitosan membranes as solid support for BTB and urease entrapment. Molekul, 15(1), 40-47.

Idris, A., Yee, H. K., \& Kee, C. M. (2015). Preparation of cellulose acetate dialysis membrane using $D$ glucose monohydrate as additive. Jurnal Teknologi, $51(6), 67-76$.

Liv, Y., \& Chen, J. Y. (2016). Enzyme immobilization on cellulose matrixes. Journal of Bioactive and Compatible Polymers, $37(6), 1-15$.

Miller, J. N. \& Miller, J. C. (2005). Statistics and chemometrics for analytical chemistry: $5^{\text {th }} \mathrm{Ed}$. Harlow; London: Pearson Education Limited.

Newman, J. D. \& Turner, A. P. F. (2005). Home blood glucose biosensors: a commercial perspective. Biosensors and Bioelectronics, 20, 2435-2453

Nguyen, H. H., Lee, S. H., Lee, U. J., Fermin, C. D., \& Kim, M. (2019). Immobilized enzymes in biosensor applications. Materials, 12(1), 1-34.

Nolte, M. C. M., Simon, P. F. W., del Toro, M. A., Gerstandt, K., \& Calmano, W. (2011). Cellulose acetate reverse osmosis membranes made by phase inversion method: effects of a shear treatment applied to the casting solution on the membrane structure and performance. Separation Science and Technology, 46, 395403.

Patel, S., Nanda, R., Sahoo, S., \& Mohapatra, E. (2016). Biosensors in health care: the milestones achieved in their development towards lab-on-chip-analysis. Biochemistry Research International, 2016, 1-12.

Paul, A., Borreli, R., Bouyanfif, H., Gottis, S., \& Sauvage, F. (2019). Tunable redox potential, optical properties, and enhanced stability of modified ferrocene-based complexes. ACS Omega, 4(12), 14780-14789.

Puls, J., Wilson, S. A., \& Holter, D. (2011). Degradation of cellulose acetate-based materials: a review. Journal of Polymer and the Environment, 19, 152-165.

Ridhuan, N. S., Razak, K. A., \& Lockman, Z. (2018). Fabrication and characterization of glucose biosensors by using hydrothermally grown $\mathrm{ZnO}$ nanorods. Scientific Reports, 8(13722), 1-12.

Wang, X., Zhu, K. X., \& Zhou, H. M. (2011). Immobilization of glucose oxidase in alginatechitosan microcapsules. International Journal of Molecular Sciences, 12(5), 3042-3054.

Wang, Y., Sun, M., Qiao, J., Ouyang, J., \& Na, N. (2018). FAD roles in glucose catalytic oxidation studied by multiphase flow of extractive electrospray ionization (MF-EESI) mass spectrometry. Chemical Science, 9(3), 594599.

Yoo, E., \& Lee, S. (2010). Glucose biosensors: an overview of use in clinical practice. Sensors, 10, 4558-4576.

Yusan, S., Rahman, M. M. Mohamad, N., Arrif, T. M., Latif, A. Z. A., Aznan, M. M. A., Wan Nik, W. S. B. (2018). Development of an amperometric glucose biosensor based on the immobilization of glucose oxidase on the Se-MCM-41 mesoporous composite. Journal of Analytical Methods in Chemistry, 2018, 1-8.

Zhang, W., Du, Y., \& Wang, M. L. (2015). On-chip highly sensitive saliva glucose sensing using multilayer films composed of single-walled carbon nanotubes, gold nanoparticles and glucose oxidase. Sensing and Bio-Sensing Research, 4, 96-102. 